\section{Conscious efforts}

Summarize yourself in the form of a title of a paper in Nature.

A fisher in the sea of neuroscience.

What was your first experiment as a child?

It was an attempt to describe the speed of fishes in an aquarium by drawing a line on paper alongside, at the same speed.

Who has been the most important mentor in your career?

Friedrich Nietzsche, when he likened scientists to prehistoric hunters. Our modern scientific activities are driven by hunting instincts that we have inherited from our ancestors.

What single scientific paper or talk changed your career path?

The Nobel prizewinning papers by Alan Hodgkin and Andrew Huxley (J. Physiol. (Lond.) 117, 500-544; 1952), in which they described nerve impulses in terms of ionic conductances, remain unsurpassed examples of beauty in science.

What's your favourite conference destination, and why?

I prefer to go to a new place each time, to avoid the risk of spoiling pleasant memories.

What book is currently on your bedside table? The Illusion of Conscious Will by Daniel M. Wegner.

Assuming the dead can be raised and/or time travel exists, who from the world outsidescience would you most like to have dinner with?

Lev Tolstoy — and on such an occasion I would stay vegetarian, of course.

You are on a plane behind two students obviously going to the same conference, who start to talk aboutyour work. What do you do?

I was in a still more frustrating situation at a meeting, when some smart-alec asked my student whether Oleg Krishtal was still alive. I could not stand the pleasure of immediate resurrection.

What one thing would you rescue from your burning laboratory?

My copy of Ion Channels of Excitable Membranes by Bertil Hille, with a personal inscription by the author.

What's the best piece of advice you've received? Keep cool!

What do you most dislike about having research published?

I quote the Russian poet Tyutchev: "A thought, once uttered, is a lie."
The Internet is the bane of scientists' lives because...

...it's a sexton of personality. Still, we shall have a lot of entertainment on the way.

What do you do to relax?

Reflect.

What's just around the corner?

An intellectual continuum whose disciplinary borders have been crushed, like the Berlin Wall.

Is there a 'tyranny of reductionism' in how scientists are trained today?

I consider reductionism as a good basis for any scientific training. The innate human drive to metaphysics has to be properly balanced.

What overlooked or underrated discovery really changed the science in which you work?

There is a story about the composer Mendelssohn, who bought a piece of herring from a market. When he got home, he found that it had been wrapped in a piece of sheet-music manuscript. Mendelssohn started to read and was overwhelmed the music turned out to be a forgotten piece by an obscure composer called J.S. Bach. This discovery led to Bach's contemporary rehabilitation. With so many people involved in science, we are unlikely to find such forgotten gems. If something important has been overlooked, it will be reinvented at a price of losing the original reference.

Which field in science (apart from your own) deserves more funding, and why?

Not a field, but an aim: the efficient conversion of solar energy, either through solidstate technologies or the genetic engineering of novel plants.

What's the one thing about science that you wish the public understood better?

I recall a story in which people whose brains were being examined by positron emission tomography were asked to look at a blank screen. An image was gradually introduced by increasing the contrast, and the subject was asked to record the instant when an image was visible. It seems that the visual cortex detects significantly weaker signals than the conscious self. The public should better understand that science is not just about knowledge, but also self-knowledge.

What would you have become, if not a scientist? I would be exploring the only thing that is not still subject to reductionist science consciousness. The only available tool for the investigation of consciousness is reflection.

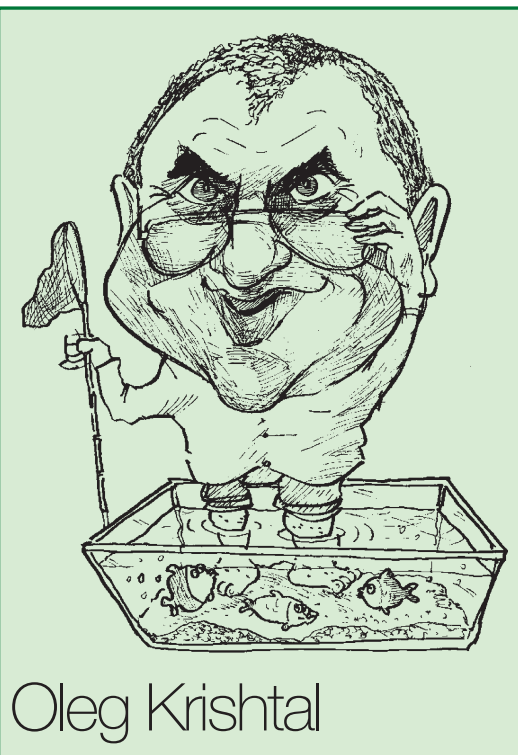

Oleg Krishtal is professor and chair of the department of cellular membranology at the Bogomoletz Institute of Physiology, Ukrainian Academy of Sciences. His research is in the fields of neuroscience, biophysics and pharmacology.

I have written a couple of books on this topic, published in Russian. One of them, a novel called Homunculus, is about a neuroscientist who discovers that his girlfriend is a smarter scientist than he is. This has been published in Russian and also in French under the title Moi et Mon Double. Another book, To the Singing of Birds, is a revelation of conscious self experiencing the times of prevailing darwinism. At the risk of seeming immodest, it awaits another Mendelssohn.

Do you have any more novels up your sleeve? So far, only commentaries to the last one: it took me nearly two years to assess what it is that has come to my mind.

What one thing would you change about Nature?

I would add a section called'Titles of rejected Letters' (peer-reviewed, of course).

What is the most interesting thing in yourfridge? Post-Communist non-filtered Ukrainian beer.

You've just been told (in confidence) that the world will end tomorrow. What would you do? Relax.

Do you have a burning ambition to do or learn something of no practical or immediate value? If so, what?

I am afraid that life is a story of getting used to having only practical ambitions.

How would you like to be remembered? As an optimist. 